\title{
FOXG1-Related Disorders: From Clinical Description to Molecular Genetics
}

\author{
C. Florian ${ }^{a, b}$ N. Bahi-Buisson ${ }^{b, c}$ T. Bienvenu $u^{a, b, d}$

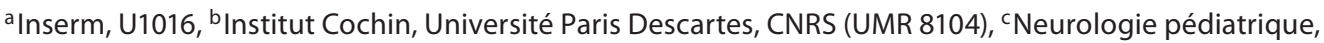 \\ Hôpital Necker-Enfants Malades, Assistance Publique - Hôpitaux de Paris, et ${ }^{d}$ Laboratoire de Biochimie et \\ Génétique Moléculaire, Hôpital Cochin, Assistance Publique - Hôpitaux de Paris, Paris, France
}

\section{Key Words \\ Chromosome 14 - Clinical features Congenital variant • Encephalopathy · FOXG1 • Human - Microcephaly • Molecular basis of disease $\cdot$ Mouse $\cdot$ Rett syndrome}

\begin{abstract}
Rett syndrome (RTT) is a severe neurodevelopmental disease that affects approximately 1 in 10,000 live female births and is often caused by mutations in the X-linked gene encoding methyl-CpG-binding protein 2 (MECP2). Mutations in loci other than MECP2 have also been found in individuals that have been labeled as atypical RTT. Among them, a mutation in the gene forkhead box G1 (FOXG1) has been involved in the molecular aetiology of the congenital variant of RTT. The FOXG1 gene encodes a winged-helix transcriptional repressor essential for the development of the ventral telencephalon in embryonic forebrain. Later, FOXG1 continues to be expressed in neurogenetic zones of the postnatal brain. Although RTT affects quasi-exclusively girls, FOXG1 mutations have also been identified in male patients. As far as we know, about 12 point mutations and 13 cases with FOXG1 molecular abnormalities (including translocation, duplication and large deletion on the chromosome 14q12) have been described in the literature. Affected individuals with FOXG1 mutations have shown dysmorphic features and Rettlike clinical course, including normal perinatal period, post-
\end{abstract}

natal microcephaly, seizures and severe mental retardation. Interestingly, the existing animal models of FOXG1 deficiency showed similar phenotype, suggesting that animal models may be a fascinating model to understand this human disease. Here, we describe the impacts of FOXG1 mutations and their associated phenotypes in human and mouse models.

Copyright $\odot 2011$ S. Karger AG, Basel

\section{History of the Syndrome}

In 2005, Shoichet et al. reported a 7-year-old girl exhibiting severe cognitive disability associated with a significant asymmetrical enlargement of the lateral ventricles, frontal and parietal myelination defects, complete agenesis of the corpus callosum, cerebral seizures, tetraplegia and microcephaly with a balanced de novo translocation $\mathrm{t}(2 ; 14)(\mathrm{p} 22 ; \mathrm{q} 12)$ with a neighboring $720-\mathrm{kb}$ inversion in chromosome 14q12 that disrupts the wingedhelix transcription factor forkhead box G1 (FOXG1) gene [Shoichet et al., 2005]. Later, three 14q12 interstitial deletions (3.1 Mb, 2.9 Mb, and 3.6 Mb) including FOXG1 (MIM 164874) were identified and characterized in 2 girls with psychomotor retardation, epilepsy, microcephaly, and unusual facial features, and in a 10-monthold male patient with mental retardation, microcephaly,

\section{KARGER}

Fax +4161306 1234

E-Mail karger@karger.ch

www.karger.com
(C) 2011 S. Karger AG, Basel

$1661-8769 / 11 / 0025-0153 \$ 38.00 / 0$

Accessible online at:

www.karger.com/msy
Thierry Bienvenu

Institut Cochin, Université Paris Descartes

24 rue du Faubourg St Jacques

FR-75014 Paris (France)

Tel. +33 1444124 79, E-Mail thierry.bienvenu@inserm.fr 
and facial dysmorphism [Bisgaard et al., 2006; Papa et al., 2008; Mencarelli et al., 2009]. Finally, the importance of the FOXG1 gene was reinforced by linking FOXG1-null mutations and the congenital variant of Rett syndrome (RTT) in 2 unrelated girls [Ariani et al., 2008]. The congenital variant is 1 of the 5 subgroups of atypical RTT, and although up to $95 \%$ of classical RTT and $40-50 \%$ of atypical RTT are caused by mutations in the methylCpG-binding protein 2 (MECP2) gene, only few girls described as congenital variants have been reported as mutated in this gene [Huppke et al., 2000; Monrós et al., 2001; Smeets et al., 2003; Rajaei et al., 2011]. Initially described by Rolando, the affected girls showed several clinical features observed in classic RTT, but in addition they were described as atonic and mentally retarded from the very first months of life [Rolando, 1985]. The most consistent RTT-like features observed in these patients were microcephaly, either of congenital onset or secondary to early postnatal deceleration of head growth, hand stereotypies, neurogenic scoliosis, and some autonomic features including hypotrophic feet, bloating, and impaired nociperception. However, because RTT is a neurodevelopmental disorder affecting almost exclusively females, large molecular screening of the FOXG1 gene were initially carried out in cohorts of female individuals suffering from typical and atypical forms of RTT [Bahi-Buisson et al., 2010; Mencarelli et al., 2010; Philippe et al., 2010], and this bias may explain why only one male patient has been reported to date with FOXG1 point mutations [Le Guen et al., 2011].

\section{Clinical Features}

\section{Microdeletions on Chromosome 14q12}

Up to now, interstitial deletions of the long arm of chromosome 14 are a quite rare finding. Reported deletions have ranged from the loss of multiple bands to smaller deletions involving a single band [Kamnasaran et al., 2001; Petek et al., 2003]. The clinical phenotype varies, but some features commonly seen include global developmental delay, hypotonia, delayed myelination, seizures, microcephaly and craniofacial anomalies. Few numbers of interstitial deletions smaller than $3.5 \mathrm{Mb}$, involving band $14 \mathrm{q} 12$ and including only few genes, have been described in the literature (table 1). In 2006, Bisgaard et al. reported an 11-month-old girl with a 14q12 interstitial deletion of 3.1 Mb. This girl showed psychomotor retardation, epilepsy, microcephaly, and unusual facial features [Bisgaard et al., 2006]. Two years later, a de novo chromosome 14 interstitial deletion of about 3.12 $\mathrm{Mb}$ has been revealed using array-based comparative genomic hybridization (CGH) analysis [Papa et al., 2008]. In this last study, the patient showed severe neurological impairment, and a distinctive facial feature very similar to the Bisgaard's case. Together, Bisgaard and Papa's studies have identified 5 genes from the commonly deleted region: FOXG1, PRKD1, SCFD1, COCH and STRN3.

More recently, a 3.6-Mb de novo deletion has been reported in a 10-month-old Caucasian male [Mencarelli et al., 2009]. This patient showed microcephaly noted before the fifth month of life, severe feeding problems and facial dysmorphisms. EEG abnormalities and epilepsy were not yet present. Importantly, the patient also showed an additional de novo deletion in 10q21.1 of about $4.8 \mathrm{Mb}$. Interestingly, the case described by Mencarelli et al. showed similarities with the other cases described in Bisgaard and Papa's studies only for few clinical features (probably due to the presence of the additional rearrangement on chromosome 10). Another de novo deletion about $2.6 \mathrm{Mb}$ was identified by array-CGH analysis in a 3-year-old female [Jacob et al., 2009]. The genes localized to this region included FOXG1 and a putative gene C23orf14 with unknown function. Developmental delay was noticed at 4 months of age. Brain magnetic resonance imaging (MRI) at 6 months showed microcephaly with appropriate structure and myelination.

In conclusion, the emerging phenotype of microdeletions in 14q12 region is characterized by severe mental retardation with a normal perinatal period followed by a phase of developmental regression at the age of 3-6 months. The phenotype includes postnatal microcephaly, postnatal growth retardation, hypotonia, and stereotypic movements. Comparison of the clinical pictures presented by these patients allowed the definition of a peculiar facial phenotype characterized by mild dysmorphisms such as bulbous nasal tip and prognathism.

\section{Duplications on Chromosome 14q12}

Duplication of the chromosomal region encompassing FOXG1 has been first reported in 1 patient with infantile spasms, severe intellectual impairment, and minor dysmorphisms [Yeung et al., 2009]. More recently, 6 cases with duplications of the $14 \mathrm{q} 12$ region containing the FOXG1 gene were described [Brunetti-Pierri et al., 2011], and a seventh case with developmental impairment and a 14q12 duplication involving the FOXG1 gene was described in the Database of Chromosomal Imbalance and Phenotype in Humans using Ensembl Resources (DECIPHER 248559) (table 2). Three cases were de- 
Table 1. Clinical summary of the patients with interstitial deletions of the long arm of chromosome 14 including the FOXG1 gene

\begin{tabular}{|c|c|c|c|c|}
\hline & Bisgaard et al. [2006] & Papa et al. [2008] & Mencarelli et al. [2009] & Jacob et al. [2009] \\
\hline Case number & $1(3.1 \mathrm{Mb})$ & $1(3.12 \mathrm{Mb})$ & $1(3.6 \mathrm{Mb})$ & $1(2.59 \mathrm{Mb})$ \\
\hline Sex & female & female & male & female \\
\hline Age & 11 months & 7 years & 10 months & 3 years \\
\hline Normal OFC at birth & $33 \mathrm{~cm}(-1 \mathrm{SD})$ & $32 \mathrm{~cm}(-1 \mathrm{SD})$ & $33 \mathrm{~cm}(-1 \mathrm{SD})$ & $32.5 \mathrm{~cm}(-1 \mathrm{SD})$ \\
\hline $\begin{array}{l}\text { Deceleration of head growth from } \\
\text { birth (microcephaly) }\end{array}$ & yes & yes & yes & yes \\
\hline Regression & no & yes ( $<6$ months) & yes ( $<3$ months) & no \\
\hline Severe intellectual disability & present & present & present & present \\
\hline Hypotonia & yes & yes & yes & yes \\
\hline Poor to absent voluntary hand use & no & yes & no & N/A \\
\hline Facial abnormalities & $\begin{array}{l}\text { prominent metopic suture, } \\
\text { apparently large ears, } \\
\text { bilateral epicanthal folds, } \\
\text { bulbous nasal tip, depressed } \\
\text { nasal bridge, tented upper } \\
\text { lip, and everted lower lip }\end{array}$ & $\begin{array}{l}\text { prominent metopic suture, large } \\
\text { ears, bilateral epicanthal folds, } \\
\text { bulbous nasal tip, depressed } \\
\text { nasal bridge, thick upper lip, } \\
\text { everted lower lip, prognathism, } \\
\text { and hypermetropia }\end{array}$ & $\begin{array}{l}\text { apparently large ears, } \\
\text { bilateral downslanting } \\
\text { palpebral fissures, bulbous } \\
\text { nasal tip, depressed nasal } \\
\text { bridge, thin upper lip, and } \\
\text { lower lip, prognathism }\end{array}$ & $\begin{array}{l}\text { low ears, synoph- } \\
\text { rys, depressed nasal } \\
\text { bridge, bulbous } \\
\text { nasal tip, thin lips, } \\
\text { and pointed chin }\end{array}$ \\
\hline Seizures & present & present (6 months) & no & present \\
\hline Stereotypic movements & dyskinetic movements & constant of hands and tongue & yes & yes (face, limb) \\
\hline Jerky movement of the upper limbs & no & yes & yes & N/A \\
\hline Bruxism & no & yes & no & yes \\
\hline Speech & no & no & no & N/A \\
\hline $\begin{array}{l}\text { Delayed myelination or } \\
\text { hypomyelination }\end{array}$ & N/A & N/A & N/A & no \\
\hline Hypoplastic corpus callosum & no & agenesis & agenesis & N/A \\
\hline $\begin{array}{l}\text { Frontal and temporal atrophy } \\
\text { with gyral simplification }\end{array}$ & no & no & absence of gyrus anguli & no \\
\hline
\end{tabular}

N/A = Not available.

Three other cases have been described, but clinical data were insufficient to be included in this table (a de novo 0.64-Mb deletion [unpublished data] and two 0.14-1.8-Mb deletions (DECIPHER database) [Mencarelli et al., 2009]).

scribed by using array CGH among over 11,000 patients $(0.027 \%)$, and 3 cases among 3,752 patients $(0.08 \%)$. The emerging phenotype of duplications is characterized by a severe developmental and intellectual impairment associated with an absence or a delay of speech. The majority of the patients with duplications on 14q12 showed developmental epilepsies and infantile spasms (4/8). Five of them were affected with body dysmorphic disorders, but did not share any facial dysmorphisms. The differences in the phenotype may be explained in part by the size of the duplications on 14q12 varying between 3.1 and 18.4 $\mathrm{Mb}$. It has been proposed that the genes SUPT16H and CHD8 may account for the varying degrees of developmental delay/mental retardation in patients with $14 \mathrm{q} 11.2$ deletions and may also be relevant for patients with duplications involving this region. The minimal duplicated region on $14 \mathrm{q}$ included only the following 3 genes: FOXG1, MAPK1IP1L and PRKD1 [Brunetti-Pierri et al., 2011].
Point Mutations in the FOXG1 Gene

Only 11 different point mutations (including the p.Gln46X) [Mari et al., 2010; F. Mari, personal communication] have been identified in the FOXG1 gene. Combining the clinical data from the literature (tables 3 and 4), we have listed the most consistent features observed on the 10 published cases with FOXG1 point mutations: (i) normal pregnancy and normal delivery, (ii) normal auxological parameters at birth, followed by severe presentation excluding the classic period of regression of typical RTT patients after a period of normal development, (iii) very limited motor development, (iv) generalized hypotonia, (v) congenital microcephaly (or early-onset deceleration of head growth progressively resulting in absolute microcephaly before 4 months of age) and (vi) relative preservation of eye contact though not as intense eye gaze as the eye pointing of classical RTT and no language (if any, limited to babbling). No girl with a mutation could either walk with support, although 2 cases can stand up 
Table 2. Clinical summary of the patients with FOXG1 duplications

\begin{tabular}{lll}
\hline & Yeung et al. [2009] & Brunetti-Pierri et al. [2011] \\
\hline Case number & 1 & 7 \\
Sex & female & 6 males, 1 female \\
Age range & 9 & 19 months-35 years \\
Normal OFC at birth & yes & 1 normal; 6 N/A \\
Deceleration of head growth from birth (microcephaly) & no & $2 / 7$ \\
Regression & yes $(3-6$ months) & $1 / 6,1 \mathrm{~N} / \mathrm{A}$ \\
Develomental delay/mental retardation & yes & $7 / 7$ \\
Hypotonia & yes & $1 / 7$ \\
Absence/delayed speech & no & $7 / 7$ \\
Walk & yes & $5 / 7$ \\
Ophthalmological abnormalities & no & Keratoconus $1 / 7$ \\
Seizures & yes $(3$ months $)$ & $4 / 7$ (1 generalized tonic-clonic seizures, \\
& & 3 infantile spasms $)$ \\
Dysmorphic features & N/A & $4 / 7$ \\
Cleft palate & no & $1 / 7$ \\
Postaxial polydactyly & no & $1 / 7$ \\
Syndactyly & yes & $1 / 7$ \\
Deletion size & $4.45 \mathrm{Mb}$ & $3.1-18.4$ Mb \\
\hline
\end{tabular}

N/A = Not available. ${ }^{a}$ Including the DECIPHER 248559 patient.

with assistance [Mencarelli et al., 2010]. They also demonstrated feeding difficulties and features of autonomic origin, such as cold and hypotrophic extremities and abdominal bloating, but no breathing disturbances.

More specifically, the 10 patients with FOXG1-point mutations showed intense hyperkinetic movement disorders with polymorphic midline stereotypies and jerklike movements mainly consisting of axial and limb myoclonia. The pattern of these stereotypies differs from those of classic RTT with no hair-pulling, rare hand-washing and a predominance of hand-pulling and pill-rolling. Moreover, they had bruxism and repetitive protrusive tongue movements. Another striking feature in FOXG1-related encephalopathy is the high prevalence of strabismus in these patients, which is usually not observed in other RTT variants. Epilepsy is also a frequent feature with generalized tonic and myoclonic seizures, with a highly variable age of onset ranging from 4 months to 14 years of age [Ariani et al., 2008]. The EEG pattern does not suggest any specific epilepsy syndrome. In the great majority of cases and in contrast with CDKL5-related disorders, seizures were easily controlled by antiepileptic drugs.

Fine analysis of brain MRI data showed significantly delayed myelination in 2 FOXG1 mutation patients investigated at 22 months of age [Bahi-Buisson et al., 2010]. These effects range from delayed myelination to global hypomyelination, combined with frontal and temporal
Table 3. Major clinical signs that characterize patients with FOXG1 point mutations (in bold in the table)

\begin{tabular}{lcl}
\hline & $\begin{array}{l}\text { Girl } \\
(\mathrm{n}=11)^{\mathrm{a}-\mathrm{d}}\end{array}$ & $\begin{array}{l}\text { Boy } \\
(\mathrm{n}=1)^{\mathrm{e}}\end{array}$ \\
\hline Head circumference at birth & $2 / 11$ & 1 \\
Postnatal microcephaly <-3 SD & $\mathbf{1 0 / 1 0}(1 \mathrm{~N} / \mathrm{A})$ & 1 \\
Eye contact and pursuit & $4 / 7(4 \mathrm{~N} / \mathrm{A})$ & 1 \\
Ability to walk & $1 / 11$ & 0 \\
Hand stereotypies & $\mathbf{1 1 / 1 1}$ & 1 \\
Jerky-like movement & $\mathbf{8 / 1 0}(1 \mathrm{~N} / \mathrm{A})$ & 1 \\
Bruxism & $10 / 11$ & 1 \\
Seizure/epilepsy & $7 / 10$ & 0 \\
Sleep disorders & $5 / 10$ & 1 \\
\hline
\end{tabular}

$\mathrm{N} / \mathrm{A}=$ Not available

${ }^{a}$ Mencarelli et al. [2010]. ${ }^{b}$ Ariani et al. [2008]. ${ }^{c}$ Bahi-Buisson et al. [2010]. ${ }^{\mathrm{d}}$ Philippe et al. [2010]. ${ }^{\mathrm{e}}$ Le Guen et al. [2011].

atrophy with gyral simplification and a hypoplastic corpus callosum (fig. 1). Previous studies also described that FOXG1 mutations are associated with corpus callosum abnormalities [Ariani et al., 2008; Philippe et al., 2010] or, in few cases, with poor development of frontal and parietal lobes [Shoichet et al., 2005]. This severe myelination delay may suggest a link between FOXG1 and oligodendrocyte maturation. Whether FOXG1 loss of function di- 
Table 4. Clinical summary of female and male patients with FOXG1 mutations

\begin{tabular}{|c|c|c|c|c|}
\hline & $\begin{array}{l}\text { Mencarelli et al. [2010], } \\
\text { Ariani et al. [2008] }\end{array}$ & $\begin{array}{l}\text { Bahi-Buisson } \\
\text { et al. [2010] }\end{array}$ & $\begin{array}{l}\text { Philippe } \\
\text { et al. [2010] }\end{array}$ & $\begin{array}{l}\text { Le Guen } \\
\text { et al. [2011] }\end{array}$ \\
\hline Case number & 5 & 3 & 2 & 1 \\
\hline Age range, years & $2.6-22$ & $3-5.8$ & $10-22$ & 3 \\
\hline Normal OFC at birth, $\mathrm{cm}$ & $33.5-34$ (one N/A) & $31.7-34(-1$ to $2 \mathrm{SD})$ & $34(-1 \mathrm{SD})$ & $33 \mathrm{~cm}$ (10th p.) \\
\hline Deceleration of head growth from birth & $4 / 5 ; 1 \mathrm{~N} / \mathrm{A}$ & $2 / 3$ & $2 / 2$ & yes \\
\hline Regression & $5 / 5$ (3-6 months) & $0 / 3$ & $2 / 2$ (4-6 months) & no \\
\hline Severe intellectual disability & $5 / 5$ & $3 / 2$ & $2 / 2$ & yes \\
\hline Relative preservation of eye contact & 1 yes; 1 no; 3 N/A & $2 / 3$ & No & yes \\
\hline Hypotonia & $3 / 4 ; 1 \mathrm{~N} / \mathrm{A}$ & $3 / 3$ & $1 / 2$ & yes \\
\hline Scoliosis & $3 / 5 ; 1 \mathrm{~N} / \mathrm{A}$ & $2 / 3$ & $0 / 2$ & no \\
\hline Ability to walk & $0 / 5$ & $0 / 3$ & $1 / 2$ & no \\
\hline Seizures (age of onset) & $2 / 5 ; 1 \mathrm{~N} / \mathrm{A}$ & 2/3 (4 and 18 months) & $1 / 2$ (2 years) & no \\
\hline Hand stereotypies & $4 / 5 ; 1 \mathrm{~N} / \mathrm{A}$ & $\begin{array}{l}3 / 3 \text { complex intermixed } \\
\text { with wringing movements } \\
\text { of fingers and mouthing }\end{array}$ & $2 / 2$ & $\begin{array}{l}\text { yes } \\
\text { hand mouthing }\end{array}$ \\
\hline Jerky movement of the upper limbs & $4 / 5 ; 1 \mathrm{~N} / \mathrm{A}$ & $3 / 3$ & $1 / 2$ & yes \\
\hline Bruxism & $4 / 5 ; 1 \mathrm{~N} / \mathrm{A}$ & $3 / 3$ & $1 / 2$ & yes \\
\hline Mood lability inconsolable crying & $2 / 5 ; 3 \mathrm{~N} / \mathrm{A}$ & $2 / 3$ & $2 / 2$ & yes \\
\hline Sleep disturbance & $1 / 5 ; 1 \mathrm{~N} / \mathrm{A}$ & $1 / 3$ & $1 / 3$ & yes \\
\hline Delayed myelination or hypomyelination & $5 \mathrm{~N} / \mathrm{A}$ & $3 / 3$ mild to severe & $\begin{array}{l}1 / 2 \text { severe, with reduced } \\
\text { white matter volume }\end{array}$ & yes, severe \\
\hline Hypoplastic corpus callosum & $3 / 5 ; 1 \mathrm{~N} / \mathrm{A}$ & $2 / 3$ & $1 / 2$ & hypoplastic \\
\hline
\end{tabular}

N/A = Not available.

rectly or indirectly affects myelination via alterations of myelin-axon interactions or both remains to be addressed by further experiments.

Altogether, association of postnatal microcephaly, dyskinetic movement disorders, stereotypic hand movements, absence of purposeful hand movement and feeding difficulties combined with some relatively preserved nonverbal communication skills and frontal gyral simplification and severe myelination delay suggest a FOXG1 deficiency.

\section{Consensus Criteria}

The large majority of FOXG1-mutation patients demonstrate a phenotype reminiscent of congenital RTT variant except one presenting a classical form of RTT [Philippe et al., 2010]. Only few girls described as congenital variants have been reported as mutated in the MECP2 gene.
Subsequently, efforts have been concentrated to define clinical criteria of FOXG1 related encephalopathy [Neul et al., 2010]. According to these consensus criteria, patients with FOXG1 mutation meet criteria for atypical RTT and present with the following specific features: (i) grossly abnormal initial development, (ii) severe psychomotor delay; (iii) inability to walk; (iv) severe postnatal microcephaly before 4 months; (v) regression in first 5 months; (vi) lack of typical intense 'RTT' eye gaze; (vii) typical RTT autonomic abnormalities including small cold hands and feet and peripheral vasomotor disturbances.

In addition to these clinical criteria, the MRI pattern, showing the combination of frontal gyral simplification with severe myelination delay most prominent in both frontal region and thin corpus callosum, constitutes a key feature of FOXG1-related encephalopathy in females as in male [Bahi-Buisson et al., 2010; Le Guen et al., 2011]. 


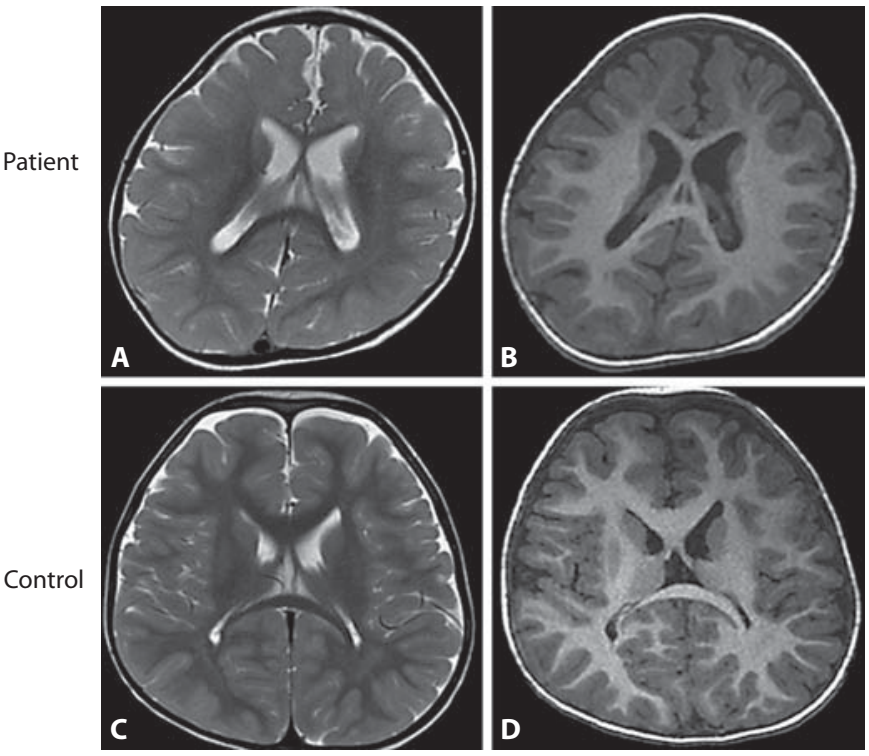

Fig. 1. Axial section of brain MRI of a 2.8-year-old patient with FOXG1 point mutation (A, B) compared with a control individual at the same age (C, D). A significant myelination defect on T2weighted axial section (A), and gyral simplification most prominent in frontal region on T1-weighted axial section (B).

\section{Structure and Functions of the FOXG1 Gene}

\section{The FOXG1 Gene}

The mammalian forkhead family includes 43 genes and belongs to the large family of 100 known forkhead genes (FOX genes) in animals [Solomon et al., 2003]. FOX genes have been identified in species ranging from worm to human. They have been described in Caenorhabditis elegans [Miller et al., 1993], Drosophila melanogaster [Weigel and Jäckle, 1989], zebrafish [Strähle et al., 1993], Xenopus [Knöchel et al., 1992], mouse [Sasaki and Hogan, 1993] and human [Hromas et al., 1993]. FOX genes are known to encode a subgroup of the helix-turn-helix class of proteins [Clark et al., 1993]. Currently, they are divided into 17 subclasses (A to Q), according to the amino acid sequence of their conserved forkhead domains [Kaestner et al., 1993]. Since the discovery of the Drosophila transcription factor forkhead, many studies have investigated the role of the forkhead box genes in organogenesis, including patterning and morphogenesis, through the regulation of proliferation and the cell fate specification [Solomon et al., 2003].

One of the FOX family, the winged-helix transcription factor forkhead box G1, FOXG1 (formerly named forebrain-restricted transcription factor BF-1), has been de- scribed to play an important role in the development of the telencephalon [Tao and Lai, 1992; Murphy et al., 1994]. Human FOXG1 gene (previously FOXG1B) is located in chromosome 14q12 and contains only 1 coding exon (exon 1 in fig. 2) [Wiese et al., 1995; Bredenkamp et al., 2007]. Four alternative transcripts for FOXG1 (exon 2 to 5) have been identified in fetal brain [Shoichet et al., 2005].

\section{Functions of the FOXG1 Protein}

Domains of the FOXG1 Protein. The FOXG1 protein consists of a 100-residue forkhead DNA-binding domain (FHD), highly conserved across all members of the FOX family. FOXG1 recruits transcriptional corepressor proteins, a histone demethylase and Groucho (Gro), via 2 further protein-binding domains, the 10-residue KDM5B (previously JARID1B)-binding domain (JBD) and the about 20-residue Gro-binding domain (GBD), respectively (fig. 2). Structurally, the FHD consists of 3 alpha helices and 1 beta hairpin ( 2 beta strands and 1 loop), whereas the GBD and JBD are random coiled. Mutations of one of these binding domains disrupt the FOXG1 protein at different sites (fig. 2). Ariani et al. have described the first FOXG1-truncating mutations in 2 patients affected by the congenital variant of RTT [Ariani et al., 2008]. In this first patient, a stop codon mutation (named p.Trp255X) impaired the DNA binding properties, while the second patient presented a 1-bp deletion (named p.Ser323ArgfsX325) causing the loss of JBD interaction domain and the misfolding of the motif responsible for GBD. More recently, Mencarelli et al. have described a new frameshift mutation (named p.Ser185GlnfsX454), a stop mutation (named p.Tyr208X) and 2 missense mutations (named p.Phe215Leu and p.Asn227Lys) in female patients [Mencarelli et al., 2010]. The same year, 3 de novo nonsense mutations and 1 frameshift mutation (named p.Trp308X, p.Tyr400X, p.Tyr416X, and p.Glu154GlyfsX300) have been described in female patients [Bahi-Buisson et al., 2010; Philippe et al., 2010], and a mutation with a cytosine duplication between the nucleosides 256 and 257 (named c.256_257dupC) generating a truncated protein (p.Gln86ProfsX34) lacking the FHD in a male patient [Le Guen et al., 2011].

The FOXG1 Transcription Factor is a Master Gene of Telencephalic Development. The vertebrate telencephalon exhibits one of the most heterogeneous collections of neurons in the entire nervous system in terms of morphology, structure, function and genetic specification. Regional specification, growth and differentiation of telencephalic divisions and subdivisions, such as the cere- 


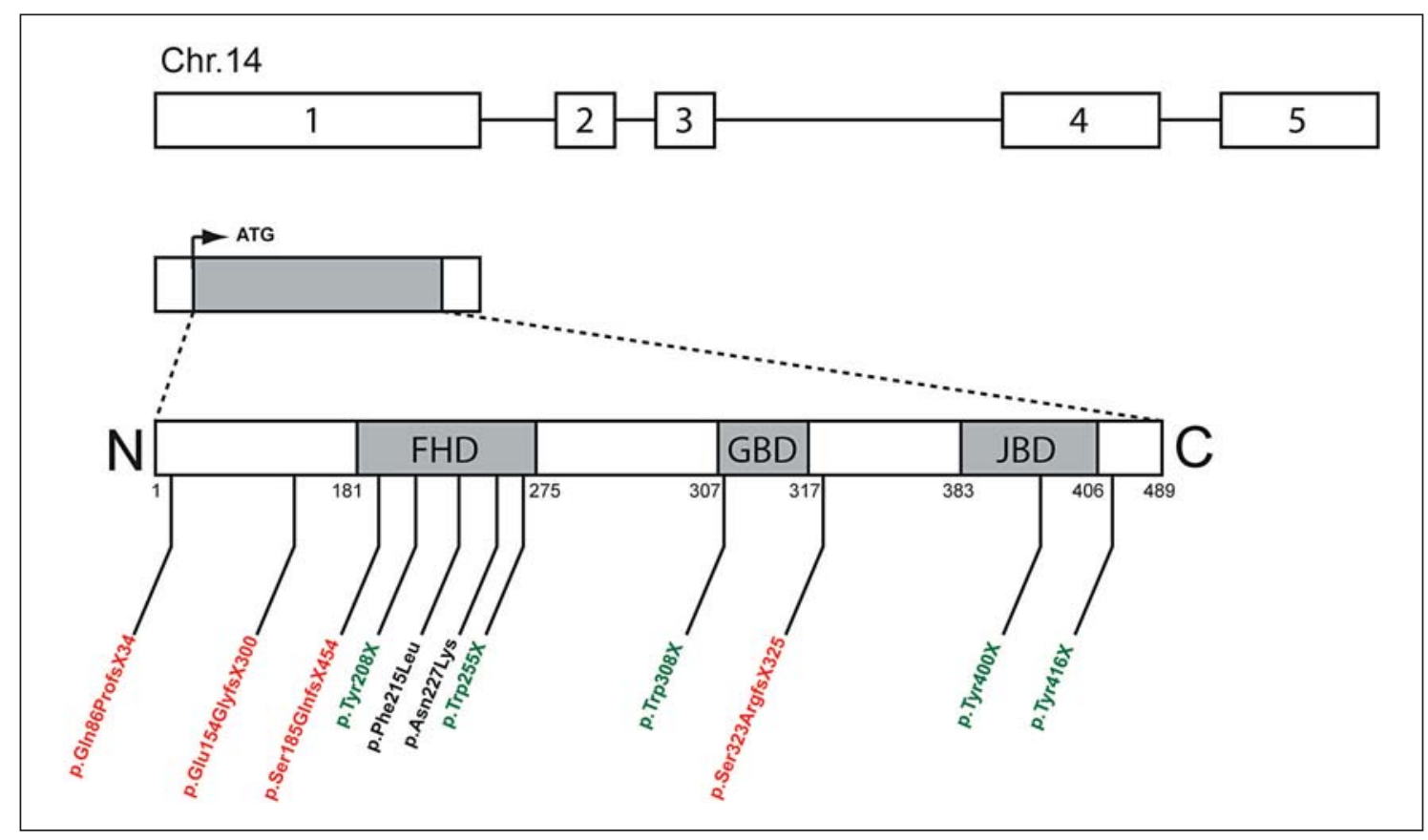

Fig. 2. Schematic representation of human FOXG1 gene and its deleterious mutations. The 489-amino-acid-long FOXG1 transcription factor (ARN NM_005249) is encoded by the intronless FOXG1 coding region (exon 1). Shaded regions indicate the 3 functional domains of the protein, i.e. the DNA-binding forkhead domain (FHD) (amino acids 181-275), the Gro-binding do-

bral cortex, are regulated by the interplay of secreted proteins produced by patterning centers and signal transduction systems deployed in the surrounding neuroepithelium. Three different signaling centers are required for correct specification of the telencephalon, and to regulate the expression of region-specific genes such as bone morphogenetic protein (BMP), wingless/int protein (WNT), extracellular signal fibroblast growth factor 8 (FGF8), and sonic hedgehog (SHH) [Ericson et al., 1995; Furuta et al., 1997; Lee et al., 2000; Walshe and Mason, 2003].

Previous studies have shown that FOXG1 is an important regulator of the progenitor-to-neuron transition in the mammal telencephalon. In the absence of FOXG1, telencephalic progenitor cells differentiate prematurely, leading to early depletion of the progenitor population, suggesting that FOXG1 promotes cell proliferation in the telecenphalon [Xuan et al., 1995]. Disruption of FOXG1 function showed an ectopic expression of BMP4 in the telencephalic neuroepithelium indicating that FOXG1 facilitates proliferation by inhibiting BMP4 expression [Xuan et al., 1995; Dou et al., 1999]. Unlike FOXG1, BMP4 main (GBD) (amino acids 307-317) and the KDM5B (formerly JARID1B) binding domain (JBD) (amino acids 383-406). Three different mutations reported in FOXG1 exon 1 are represented: frameshift mutations (red), stop codon mutations (green) and missense mutations (black). Amino acid numbers are indicated below the protein representation. was shown to inhibit telencephalic progenitor cell proliferation [Furuta et al., 1997]. Furthermore, FOXG1 has been proposed to play a role in ventral telencephalon development, by inducing the expression of FGF8 [Hébert and Fishell, 2008]. FOXG1 is required for the FGF8 expression and, conversely, FOXG1 expression is itself regulated by FGF signaling [Martynoga et al., 2005]. Initially, FOXG1 expression was restricted to the most rostral region of the neural tube. By embryonic day 9 (E9), the FOXG1 expression domain is composed of the telencephalic neuroepithelium, including the progenitor cells of the cerebral cortex, the basal ganglia and the olfactory bulb [Shimamura et al., 1995; Dou et al., 1999]. After E9.5, expression of FOXG1 declines in the dorsomedial telencephalon and the dorsal midline, showing a shallow dorsal-medial gradient and giving a high level of FOXG1 in the ventral telencephalon. At E12.5, FOXG1 is present in the neural progenitors of the telencephalon and absent from the rest of the neural tube. Finally, FOXG1 expression remains restricted to cells derived from the telencephalic neuroepithelium, including cerebral cortex and the hippocampus [Dou et al., 1999]. 
Moreover, FOXG1 interacts with the members of the Gro/transducin-like enhancer of split family of transcription factors, which are involved in a number of developmental pathways [Tao and Lai, 1992; Yao et al., 2001; Hanashima et al., 2002, 2004; Marçal et al., 2005] and may regulate different processes such as proliferation rate, differentiation rate, and apoptosis. FOXG1 is nuclear in progenitor cells but cytoplasmic in differentiating cells, suggesting that FOXG1 may be having a distinct function in the cytosol [Regad et al., 2007]. While FOXG1 continues to be expressed in neurons postnatally and through adulthood, its role in differentiated neurons is still not well known. Nevertheless, a recent study showed that FOXG1 promotes survival of postmitotic neurons [Dastidar et al., 2011]. The authors concluded that the survival promoting activity of FOXG1 is mediated by the PI3 kinase-Akt signaling pathway, and also that FOXG1 is a downstream target of IGF1-mediated signal transduction.

\section{Genetics of FOXG1 Disorders}

\section{Mode of Inheritance}

FOXG1-related disorder is an autosomal dominant disorder. Up to now, all described cases are simplex cases (i.e., a single occurrence in a family), resulting from a de novo mutation. Because of the possibility of germline mosaicism, it is appropriate to offer prenatal diagnosis to couples who had a child with a FOXG1-related disorder regardless of whether the disease-causing mutation has been detected in a parent.

\section{Frequency of FOXG1 Mutations and Molecular \\ Diagnosis}

The prevalence of these FOXG1-related disorders has not been estimated, but these disorders appear to be rare, but not exceptional. The diagnosis of all FOXG1-related disorders relies on molecular genetic and cytogenetic testing. Sequence analysis and deletion/duplication testing for exonic, and whole-gene deletions/duplications are available on a clinical basis. Point mutations in the FOXG1 coding region (alias exon 1) are detected by bidirectional sequencing and/or mutation scanning (e.g. DHPLC). Nevertheless, supplemental investigations on the noncoding exons (exon 2 to 5) of FOXG1 gene would be helpful to update the molecular etiology of Rett syndrome or Rett syndrome-like phenotypes.

Deletion and duplication analysis are carried out by a variety of methods including real-time quantitative PCR, quantitative multiplex fluorescent PCR and/or CGH-mi- croarray. Once a putative pathogenic mutation has been identified in a proband, it is appropriate to offer testing to all first-degree relatives regardless of their clinical status.

\section{Genotype-Phenotype Correlation}

Although clinical features are quite homogeneous, FOXG1-related encephalopathy demonstrates variable degree of severity. Indeed, the more severely affected patients have congenital microcephaly, virtually no visual contact and poor head control combined with severe congenital microcephaly, simplified gyral pattern and hypomyelination. At the other end of the spectrum, the less severely affected patients had a significantly better eye contact and babbling, no epilepsy, developed some purposeful hand function and were able to take some steps with support. Consistent with this, myelination was mildly delayed in the centrum semi-ovale, and no gyral defect was observed. Recently, Philippe et al. have reported a patient with an RTT presentation carrying the late truncating mutation p.Tyr400X [Philippe et al., 2010]. This patient, considered to have classical RTT according to the revised diagnostic criteria for classical and variant RTT, is a 10-year-old girl, considered to be a normal child until the age of 6 months, when developmental delay was noticed. However, the same mutation has recently been identified in a patient with a milder RTT phenotype according with 'forme frustre' and sharing strikingly similar facial features resembling the Kleefstra syndrome due to EHMT1 gene [Mari et al., 2010; personal communication]. Although genotype-phenotype correlation is difficult to establish with the few number of FOXG1 mutated cases, all the recent literatures suggest that the mutation does not predict the severity of the phenotype, suggesting that additional factors might contribute to the severity of the FOXG1-related disorders.

\section{Management and Treatment}

Unfortunately, there are currently no specific treatments that halt or reverse the progression of the disease, and so management is mainly symptomatic and individualized, focusing on aiming to optimize each patient's abilities. A dynamic multidisciplinary approach is most effective, with specialist input from dietitians, physiotherapists, and occupational therapists.

Attention needs to be paid to nutritional problems and the development of spasticity, both of which can have a major impact on quality of life in disabled patients. Psy- 
chosocial support for the families is an integral part of the management. Pharmacological approaches to managing problems associated with FOXG1-related disorders include melatonin for sleep disturbances, and anti-epileptic drugs for seizures.

\section{State of Research and Mouse Models}

Consistent with the clinical human observations described above, previous studies have shown that a null mutation in the Foxg1 gene in a mouse model causes severe defects in the development of telencephalic structures (e.g. the cerebral cortex and basal ganglia) and mice die at birth [Xuan et al., 1995; Martynoga et al., 2005]. From E10.5 to the perinatal death, the Foxg1 homozygote null telencephalon is remarkably reduced in size. Mice lacking Foxg1 display an expansion of dorsal telencephalic markers while ventral cell fates are not specified, leading to morphological defects of telencephalic structures [Xuan et al., 1995; Dou et al., 1999; Hanashima et al., 2002, 2004, 2007; Ahlgren et al., 2003; Hébert and Fishell, 2008]. These defects are accompanied by a perturbation of signaling centers, such as Wnt and Bmp expression [Hanashima et al., 2007], correlating with an increased Bmp activity within the telencephalon [Dou et al., 1999], as well as a loss of Shh expression within the ventral telencephalon [Huh et al., 1999]. Moreover, the Foxg1 ${ }^{-1-}$ knockout mouse has no recognizable olfactory structures, such as epithelium, bulb, or vomeronasal organs [Xuan et al., 1995; Duggan et al., 2008]. This is attributed to a reduction of progenitor cell proliferation (as neurogenesis begins at E10.5 in the rostral telencephalon) in both the dorsal and ventral structures, an acceleration of differentiation of telencephalic progenitors in the dorsal telencephalon, and a reduction of apoptosis in the rostral telencephalon [Hanashima et al., 2004; Martynoga et al., 2005]. At E12.5, the expression domain of the dorsal marker Emx2 was also extended more ventrally in the Foxg1 mutant, suggesting that the Foxg1 mutation causes a transformation of the dorsal telencephalon to a more ventral fate [Xuan et al., 1995].

As the homozygote mice remained cyanotic and died within minutes after birth [Xuan et al., 1995], new genetic models have been proposed for postnatal studies. Hébert and McConnell generated the Foxg1 heterozygote null mice by replacing the intronless Foxgl coding region with Cre (named Foxg1 ${ }^{+/ C r e}$, C57/BL6 background) [Hébert and McConnell, 2000]. The authors showed that $\mathrm{Foxg1}^{+/ \mathrm{Cre}}$ mice confer a deletion of the Foxg1 gene spe- cifically from the telencephalon and from other head structures, including the developing lens, retina, ear, olfactory epithelium, mid-hindbrain junction, facial and head ectoderm. Interestingly, the same phenotype was observed on multiple strains of adult $\mathrm{Foxgl}^{+/-}$mice, in which the Foxg1 coding region was replaced either with the tetracycline transactivation (Foxg1 ${ }^{+/ t T A}$, C57/BL6 background) [Hanashima et al., 2002] or with lacZ (Foxg1 ${ }^{+/ l a c Z}$, Swiss Webster background) [Xuan et al., 1995]. Indeed, Foxg1 ${ }^{+/ C r e}$ and Foxg1 $1^{+/ l a c Z}$ mice showed the same reduction of the dentate gyrus (DG) size, correlated with a loss of postnatal DG neurogenesis, suggesting that the effect of Foxg1 haploinsufficiency on DG size and postnatal hippocampal neurogenesis is not specific to a mouse strain [Shen et al., 2006]. It is well accepted that the subventricular zone (SZ) plays an important role during the period of neocortical neurogenesis, by containing stem and progenitor cells that generate neuroblasts throughout life. Interestingly, a large proportion of the cortical neurons (from the layer II/III) are born in the SZ [Miller, 1989; Tarabykin et al., 2001; Nieto et al., 2004; Noctor et al., 2004; Zimmer et al., 2004; Englund et al., 2005; Ferrere et al., 2006; Martinez-Cerdeno et al., 2006]. $\mathrm{Foxg1}^{+/ \mathrm{Cre}}$ mice also display a specific reduction in the thickness of cortical layer II/III [Shen et al., 2006; Eagleson et al., 2007], suggesting the population of the progenitor cells in the SZ is affected in Foxg1 ${ }^{+/ C r e}$ mice [Siegenthaler et al., 2008]. Thus, microcephaly observed in Foxg ${ }^{+/-}$mice may result from specific defects in progenitor cells. Finally, Foxg1 ${ }^{+/ t T A}$ mice showed hyperlocomotion and impaired habits in the open field, and a severe deficit in contextual fear-conditioning, which are suggestive of an impaired amygdala and/or hippocampal function [Shen et al., 2006]. Hence, microcephaly and cognitive function deficits are observed in both mice with haploinsufficiency of Foxg1 [Shen et al., 2006] and humans with FOXG1 mutations [Shoichet et al., 2005].

Although the first study reported that cortical development appears to be normal in Foxg1 heterozygous null mice [Xuan et al., 1995; Hébert and McConnell, 2000; Hanashima et al., 2002, 2004], other studies have described the disruption of the telencephalon development to Foxg1 haploinsufficiency. The first one reported a telencephalic hypoplasia in both hypomorphic and null-Fgf8 mice, which is likely due, at least partially, to an alteration of Foxg1 expression [Storm et al., 2006]. In the second report, cerebral microcephaly and impaired postnatal hippocampal neurogenesis were demonstrated in adult Foxg1 haploinsufficient mice [Shen et al., 2006]. Finally, the third study revealed a reduction of the volume of the prosen- 
cephalon, including the cerebral cortex, hippocampus and striatum in the Foxgl heterozygous mice [Eagleson et al., 2007]. These last 3 studies are all consistent with the phenotype associated with Foxg1 haploinsufficiency in humans, suggesting that this knockout model may be a fascinating model to understand this human disease.

\section{Conclusion}

Point mutations, deletions and duplications spanning FOXG1 have been reported in patients with developmental disorders. Although the phenotype overlaps both classical and congenital forms of RTT, the large majority of patients with point mutations and deletions present specific features including severe psychomotor delay, severe postnatal microcephaly, stereotypic movements, and dyskinetic movement disorders. In addition to these clinical criteria, the brain MRI pattern, showing the combination of frontal gyrus simplification with severe myelin- ation delay and thin corpus callosum, constitutes a key feature of FOXG1-related disorders. Although classical RTT has been described quasi-exclusively in girls, FOXG1-related mutations have been identified in both female and male patients, showing the importance of FOXG1 screening in both female and male patients with an emerging developmental profile suggestive of congenital variant of RTT. As a rare disease, congenital variant of RTT presents a small number of reported cases making difficult the relationship between the genotype and the phenotype. As for the FOXG1 in this atypical form of RTT, several studies have shown a crucial role in earlier developing forebrain, in promoting neural precursor proliferation and cerebral cortex expansion. Finally, investigations that are based on several Foxg1 haploinsufficient mouse models and on human deficient cells (such as FOXG1-deficient induced pluripotent stem cells) should improve our understanding of the consequences of FOXG1 dysfunction and propose new advances in the development of therapeutic strategies.

\section{References}

-Ahlgren S, Vogt P, Bronner-Fraser M: Excess FoxG1 causes overgrowth of the neural tube. J Neurobiol 57:337-349 (2003).

-Ariani F, Hayek G, Rondinella D, Artuso R, Mencarelli MA, et al: FOXG1 is responsible for the congenital variant of Rett syndrome. Am J Hum Genet 83:89-93 (2008).

-Bahi-Buisson N, Nectoux J, Girard B, Van Esch $\mathrm{H}$, De Ravel T, et al: Revisiting the phenotype associated with FOXG1 mutations: two novel cases of congenital Rett variant. Neurogenetics 11:241-249 (2010).

- Bisgaard AM, Kirchhoff M, Tumer Z, Jepsen B, Brondum-Nielsen $\mathrm{K}$, et al: Additional chromosomal abnormalities in patients with a previously detected abnormal karyotype, mental retardation, and dysmorphic features. Am J Med Genet A 140:2180-2187 (2006).

-Bredenkamp N, Seoighe C, Illing N: Comparative evolutionary analysis of the FoxG1 transceiption factor from diverse vertebrates identifies conserved recognition sites for microRNA regulation. Dev Genes Evol 217: 227-233 (2007).

-Brunetti-Pierri N, Paciorkowski AR, Ciccone R, Mina ED, Bonaglia MC, et al: Duplications of FOXG1 in $14 \mathrm{q} 12$ are associated with developmental epilepsy, mental retardation, and severe speech impairment. Eur J Hum Genet 19:102-107 (2011).

-Clark KL, Halay ED, Lai E, Burley SK: Co-crystal structure of the HNF-3/fork head DNA-recognition motif resembles histone H5. Nature 364:412-420 (1993).
Dastidar SG, Landrieu PM, D’Mello SR: Foxg1 promotes the survival of postmitotic neurons. J Neurosci 31:402-413 (2011).

Dou CL, Li S, Lai E: Dual role of brain factor-1 in regulating growth and patterning of the cerebral hemispheres. Cerebral Cortex 9:543550 (1999).

Duggan CD, DeMaria S, Baudhuin A, Stafford $\mathrm{D}$, Ngai J: Foxg1 is required for development of the vertebrate olfactory system. J Neurosci 28:5229-5239 (2008).

Eagleson KL, Schlueter McFadyen-Ketchum LJ, Ahrens ET, Mills PH, Does MD, et al: Disruption of Foxg1 expression by knock-in of cre recombinase: effects on the development of the mouse telencephalon. Neuroscience 148:385-399 (2007).

- Englund C, Fink A, Lau C, Pham D, Daza RA, et al: Pax6, Tbr2, and Tbr1 are expressed sequentially by radial glia, intermediate progenitor cells, and postmitotic neurons in developing neocortex. J Neurosci 25:247-251 (2005).

Ericson J, Muhr J, Jessell TM, Edlund T: Sonic hedgehog, a common signal for ventral patterning along the rostrocaudal axis of the neural tube. Int J Dev Biol 39:809-816 (1995).

Ferrere A, Vitalis T, Gingras H, Gaspar P, Cases O: Expression of Cux-1 and Cux-2 in the developing somatosensory cortex of normal and barrel-defective mice. Anat Rec A Discov Mol Cell Evol Biol 288:158-165 (2006).

Furuta Y, Piston DW, Hogan BL: Bone morphogenetic proteins (BMPs) as regulators of dorsal forebrain development. Development 124:2203-2212 (1997).
Hanashima C, Shen L, Li SC, Lai E: Brain factor- 1 controls the proliferation and differentiation of neocortical progenitor cells through independent mechanisms. J Neurosci 22:6526-6536 (2002).

Hanashima C, Li SC, Shen L, Lai E, Fishell G: Foxg1 suppresses early cortical cell fate. Science 303:56-59 (2004).

Hanashima C, Fernandes M, Hébert JM, Fishell $\mathrm{G}$ : The role of Foxg1 and dorsal midline signaling in the generation of Cajal-Retzius subtypes. J Neurosci 27:1103-1111 (2007).

Hébert JM, Fishell G: The genetics of early telencephalon patterning: some assembly required. Nat Rev Neurosci 9:678-685 (2008).

- Hébert JM, McConnell SK: Targeting of cre to the Foxg1 (BF-1) locus mediates loxP recombination in the telencephalon and other developing head structures. Dev Biol 222:296306 (2000).

-Hromas R, Moore J, Johnston T, Socha C, Klemsz M: Drosophila forkhead homologues are expressed in a lineage-restricted manner in human hematopoietic cells. Blood 81:28542859 (1993).

Huh S, Hatini V, Marcus RC, Li SC, Lai E: Dorsal-ventral patterning defects in the eye of $B F-1$-deficient mice associated with a restricted loss of shh expression. Dev Biol 211: 211-253 (1999).

-Huppke P, Laccone F, Krämer N, Engel W, Hanefeld F: Rett syndrome: Analysis of MECP2 and clinical characterization of 31 patients. Hum Mol Genet 9:1369-1375 (2000). 
-Kaestner KH, Lee KH, Schlöndorff J, Hiemisch H, Monaghan AP, Schütz G: Six members of the mouse forkhead gene family are developmentally regulated. Proc Natl Acad Sci USA 90:7628-7631 (1993).

- Kamnasaran D, O’Brien PC, Schuffenhauer S, Quarrell O, Lupski JR, et al: Defining the breakpoints of proximal chromosome $14 \mathrm{q}$ rearrangements in nine patients using flowsorted chromosomes. Am J Med Genet 102: 173-182 (2001).

- Knöchel S, Lef J, Clement J, Klocke B, Hille S, et al: Activin A induced expression of a fork head related gene in posterior chordamesoderm (notochord) of Xenopus laevis embryos. Mech Dev 38:157-165 (1992).

- Jacob FD, Ramaswany V, Andersen J, Bolduc FV: Atypical Rett syndrome with selective FOXG1 deletion detected by comparative genomic hybridization: case report and review of literature. Eur J Hum Genet 17:1577-1581 (2009).

-Lee SM, Toles S, Groves E, McMahon AP: A local Wnt-3a signal is required for development of the mammalian hippocampus. Development 127:457-467 (2000).

Le Guen T, Bahi-Buisson N, Nectoux J, Boddaert N, Fichou Y, et al: A FOXG1 mutation in a boy with congenital variant of Rett syndrome. Neurogenetics 12:1-8 (2011).

- Marçal N, Patel H, Dong Z, Belanger-Jasmin S, Hoffman B, et al: Antagonistic effects of Grg6 and Groucho/TLE on the transcription repression activity of brain factor 1/FoxG1 and cortical neuron differentiation. Mol Cell Biol 25:10916-10929 (2005).

Mari F, Bjørgo K, Pancrazi L, Mencarelli MA, Ariani F, et al: FOXG1 mutation leading to reduced chromatin affinity causes 'Rett frust' overlapping with EHMT1 phenotype. Poster presentation (2nd European Conference on Rett Syndrome, Edinburgh, Scotland 2010).

-Martinez-Cerdeno V, Noctor SC, Kriegstein AR: The role of intermediate progenitor cells in the evolutionary expansion of the cerebral cortex. Cereb Cortex 16 (suppl 1):i152-i161 (2006).

- Martynoga B, Morrison H, Price DJ, Mason JO: Foxg1 is required for specification of ventral telencephalon and region-specific regulation of dorsal telencephalic precursor proliferation and apoptosis. Dev Biol 283:113-127 (2005).

-Mencarelli MA, Kleefstra T, Katzari E, Papa FT, Cohen M, et al: 14q12 Microdeletion syndrome and congenital variant of Rett syndrome. Eur J Med Genet 52:148-152 (2009).

-Mencarelli MA, Spanhol-Rosseto A, Artuso R, Rondinella D, De Filippis R, et al: Novel FOXG1 mutations associated with the congenital variant of Rett syndrome. J Med Genet 47:49-53 (2010).

Miller MW: Effects of prenatal exposure to ethanol on neocortical development. II. Cell proliferation in the ventricular and subventricular zones of the rat. J Comp Neurol 287:326338 (1989).
Miller LM, Gallegos ME, Morisseau BA, Kim SK: lin-31, a Caenorhabditis elegans HNF-3/ fork head transcription factor homolog, specifies three alternative cell fates in vulval development. Genes Dev 7:933-947 (1993).

Monrós E, Armstrong J, Aibar E, Poo P, Canós I, Pineda M: Rett syndrome in Spain: mutation analysis and clinical correlations. Brain Dev 23 Suppl 1:S251-S253 (2001).

- Murphy DB, Wiese S, Burfeind P, Schmundt D, Mattei MG, et al: Human brain factor 1, a new member of the fork head gene family. Genomics 21:551-557 (1994).

Neul JL, Kaufmann WE, Glaze DG, Christodoulou J, Clarke AJ, et al: Rett syndrome: revised diagnostic criteria and nomenclature. Ann Neurol 68:944-950 (2010).

Nieto M, Monuki ES, Tang H, Imitola J, Haubst $\mathrm{N}$, et al: Expression of Cux-1 and Cux-2 in the subventricular zone and upper layers II-IV of the cerebral cortex. J Comp Neurol 479:168180 (2004).

- Noctor SC, Martinez-Cerdeno V, Ivic L, Kriegstein AR: Cortical neurons arise in symmetric and asymmetric division zones and migrate through specific phases. Nat Neurosci 7:136-144 (2004).

Papa FT, Mencarelli MA, Caselli R, Katzaki E, Sampieri K, et al: A $3 \mathrm{Mb}$ deletion in $14 \mathrm{q} 12$ causes severe mental retardation, mild facial dysmorphisms and Rett-like features. Am J Med Genet A 146:1994-1998 (2008).

Petek E, Plecko-Startinig B, Windpassinger C, Egger H, Wagner K, Kroisel PM: Molecular characterisation of a $3.5 \mathrm{Mb}$ interstitial $14 \mathrm{q}$ deletion in a child with several phenotypic anomalies. J Med Genet 40:e47 (2003).

-Philippe C, Amsallem D, Francannet C, Lambert L, Saunier A, et al: Phenotypic variability in Rett syndrome associated with FOXG1 mutations in females. J Med Genet 47:59-65 (2010).

Rajaei S, Erlandson A, Kyllerman M, Albage M, Lundstrom I, et al: Early infantile onset 'congenital' Rett syndrome variants: Swedish experience through four decades and mutation analysis. J Child Neurol 1:65-71 (2011).

-Regad T, Roth M, Bredenkamp N, Illing N, Papalopulu N: The neural progenitor-specifying activity of FoxG1 is antagonistically regulated by CKI and FGF. Nat Cell Biol 5:531540 (2007).

Rolando S: Rett syndrome: report of eight cases. Brain Dev 7:290-296 (1985).

Sasaki H, Hogan BL: Differential expression of multiple fork head related genes during gastrulation and axial pattern formation in the mouse embryo. Development 118:47-59 (1993).

-Shen L, Nam HS, Song P, Moore H, Anderson SA: FoxG1 haploinsufficiency results in impaired neurogenesis in the postnatal hippocampus and contextual memory deficits. Hippocampus 16:875-890 (2006).

Shimamura K, Hartigan DJ, Martinez S, Puelles L, Rubenstein JL: Longitudinal organization of the anterior neural plate and neural tube. Development 121:3923-3933 (1995).
Shoichet SA, Kunde SA, Viertel P, Schell-Apacik $C$, von Voss H, et al: Haploinsufficiency of novel FOXG1B variants in a patient with severe mental retardation, brain malformations and microcephaly. Hum Genet 117: 536-544 (2005).

- Siegenthaler JA, Tremper-Wells BA, Miller MW: Foxg1 haploinsufficiency reduces the population of cortical intermediate progenitor cells: effect of increased p21 expression. Cereb Cortex 18:1865-1875 (2008).

-Smeets E, Schollen E, Moog U, Matthijs G, Herbergs J, et al: Rett syndrome in adolescent and adult females: clinical and molecular genetic findings. Am J Med Genet A 122:227233 (2003).

-Solomon KS, Logsdon JM Jr, Fritz A: Expression and phylogenetic analyses of three zebrafish FoxI class genes. Dev Dyn 228:301-307 (2003).

-Storm EE, Garel S, Borello U, Hébert JM, Martinez $S$, et al: Dose-dependent functions of Fgf8 in regulating telencephalic patterning centers. Development 133:1831-1844 (2006).

-Strähle U, Blader P, Henrique D, Ingham PW: Axial, a zebrafish gene expressed along the developing body axis, shows altered expression in cyclops mutant embryos. Genes Dev 7:1436-1446 (1993).

- Tao W, Lai E: Telencephalon-restricted expression of BF-1, a new member of the HNF-3/ fork head gene family, in the developing rat brain. Neuron 8:957-966 (1992).

Tarabykin V, Stoykova A, Usman N, Gruss P: Cortical upper layer neurons derive from the subventricular zone as indicated by Svet 1 gene expression. Development 128:19831993 (2001).

Walshe J, Mason I: Unique and combinatorial functions of $F g f 3$ and $F g f 8$ during zebrafish forebrain and development. Development 130:4337-4349 (2003).

Weigel D, Jäckle H: Novel homeotic genes in Drosophila melanogaster. Biochem Cell Biol 67:393-396 (1989).

-Wiese S, Murphy DB, Schlung A, Burfeind P, Schmundt $D$, et al: The genes for human brain factor 1 and 2, members of the fork head gene family, are clustered on chromosome 14q. Biochim Biophys Acta 1262:105-112 (1995).

Xuan S, Baptista CA, Balas G, Tao W, Soares VC, Lai E: Winged helix transcription factor BF-1 is essential for the development of the cerebral hemispheres. Neuron 14:1141-1152 (1995).

-Yao J, Lai E, Stifani S: The winged-helix protein brain factor 1 interacts with groucho and hes protein to repress transcription. Mol Cell Biol 21:164-176 (2001).

Yeung A, Bruno D, Scheffer IE, Carranza D, Burgess $\mathrm{T}$, et al: $4.45 \mathrm{Mb}$ microduplication in chromosome band $14 \mathrm{q} 12$ including FOXG1 in a girl with refractory epilepsy and intellectual impairment. Eur J Med Genet 52: 440-442 (2009).

Zimmer C, Tiveron MC, Bodmer R, Cremer H: Dynamics of Cux2 expression suggests that an early pool of SVZ precursors is fated to become upper cortical layer neurons. Cereb Cortex 14:1408-1420 (2004). 